\title{
Comparative effects of recombinant human brain natriuretic peptide and dobutamine on acute decompensated heart failure patients with differsent blood BNP levels
}

Hai-Yan Pan ${ }^{1}$, Jian-Hua Zhu ${ }^{1 *}$, Yong Gu${ }^{1}$, Xiao-Hong Yu ${ }^{1}$, Min Pan $^{1}$ and Hong-Yin Niu ${ }^{2}$

\begin{abstract}
Background: Recombinant human B-type natriuretic peptide (rhBNP) has been indicated for the treatment of acute decompensated heart failure (ADHF). However, the therapeutic efficacy of intravenous rhBNP is not always satisfactory in patients with extremely high blood BNP levels. In this study, we evaluated the effects of rhBNP on patients with different BNP levels.

Methods: One hundred and five patients with ADHF whose left ventricular ejection fraction (LVEF) was $<40 \%$, were assigned to a high BNP group (BNP $\leq 3000 \mathrm{pg} / \mathrm{mL}$ ) or an extra-high BNP group (BNP > $3000 \mathrm{pg} / \mathrm{mL}$ ), depending on their admission plasma BNP levels. Each group was then subdivided into rhBNP or dobutamine subgroups according to intravenous administration with either rhBNP or dobutamine for 24-72h. In the high BNP group, 58 patients were randomized to subgroup rhBNP $(n=28)$ and subgroup dobutamine $(n=30)$. In the extra-high BNP group, 47 patients were randomized to subgroup rhBNP $(n=24)$ and subgroup dobutamine $(n=23)$. The effects of rhBNP and dobutamine on patients in the high and extra-high BNP groups were compared.
\end{abstract}

Results: In the high BNP group, rhBNP was more efficient than dobutamine at improving NYHA classification $(P<0.05)$, decreasing plasma BNP levels $(P<0.05)$, increasing $\operatorname{LVEF}(P<0.05)$, and reducing hospital length of stay $(P<0.05)$.

However, rhBNP displayed no superior therapeutic efficacy to dobutamine in the extra-high BNP group. Adverse cardiovascular events in patients treated with rhBNP were similar to adverse events in patients treated with dobutamine in both the high and extra-high BNP groups.

Conclusions: rhBNP was more efficient than dobutamine at improving heart function in patients with ADHF when plasma BNP was $\leq 3000 \mathrm{pg} / \mathrm{mL}$. However, rhBNP treatment showed no advantages over dobutamine when plasma BNP reached extremely high levels (>3000 pg/mL).

Trial registration: ClinicalTrials.gov Identifier: NCT01837849.

Keywords: Acute decompensated heart failure, Recombinant human brain natriuretic peptide, Dobutamine

\section{Background}

Acute decompensated heart failure (ADHF) is associated with significant morbidity and mortality and remains a common cause of hospitalization worldwide. As a result, therapies targeting both symptoms and cardiovascular outcomes are greatly needed. Two such treatments are

\footnotetext{
* Correspondence: dr.zhujianhua@gmail.com

'Department of Cardiology, Affiliated Hospital of Nantong University, and Institute of Cardiovascular Research, Nantong University, Jiangsu 226001, China Full list of author information is available at the end of the article
}

dobutamine and recombinant human brain natriuretic peptide (rhBNP).

Dobutamine is a synthetic catecholamine that acts mainly through stimulation of $\beta 1$-receptors and partly through $\beta 2$-receptors to produce dose-dependent positive inotropic and chronotropic effects [1]. It has long been used as a potent positive inotrope for the management of severe heart failure. rhBNP is a recombinant formulation of BNP that is identical to the endogenous hormone released from the cardiac ventricle in response 
to increases in wall stress, hypertrophy, and volume overload [2]. It is a potent vasodilator that is proven to rapidly reduce cardiac filling pressures and improve dyspnea in patients with ADHF [3]. In 2005, rhBNP was recommended in the ADHF treatment guidelines by the European Society of Cardiology [4].

Some evidence suggests that rhBNP is more effective than dobutamine in the treatment of heart failure [5-7]. However, in our clinical work, we have found that the effects of rhBNP are not always satisfactory in patients with extremely high blood BNP levels, with the heart function of some patients not improved until rhBNP is replaced by dobutamine. Although comparison of rhBNP and dobutamine in ADHF patients has been reported in several studies [5-7], no comparative study has been performed on ADHF patients with different plasma BNP levels. Thus, the purpose of this study was to determine the therapeutic efficacy of rhBNP in ADHF patients with different plasma BNP levels in comparison to that of dobutamine in order to provide valuable information for the treatment of heart failure.

\section{Methods}

\section{Patient selection}

Between January 2011 and June 2012, patients with ADHF who required hospitalization were enrolled in the study. The mean age was $66 \pm 13$ years (range $=29-88$ ). The ADHF etiology included idiopathic dilated cardiomyopathy (IDC), coronary heart disease (CHD), fulminant viral myocarditis (FVM), hyperthyroid heart disease (HHD), and valvulopathy. All patients were classified as New York Heart Association (NYHA) class III-IV and had an ejection fraction of $<40 \%$. Exclusion criteria included intravenous administration with rhBNP or dobutamine in the 2 weeks before study entry, acute myocardial infarction, significant valvular stenosis, serious ventricular arrhythmia (frequent ventricular premature beat of $>5 \mathrm{bpm}$, nonsustained and sustained ventricular tachycardia), blood pressure $<95 / 60 \mathrm{mmHg}$ or $>140 / 90 \mathrm{mmHg}$, shock, hypovolemia, and hepatic or renal impairment [alanine aminotransferase or aspartate aminotransferase $>2$ times the upper limit of the normal value, serum creatinine $>177 \mu \mathrm{mol} / \mathrm{L}(2.0 \mathrm{mg} / \mathrm{dl})$ for man or $>146 \mu \mathrm{mol} / \mathrm{L}(1.7 \mathrm{mg} / \mathrm{dl})$ for women]. In addition, pregnant and lactating women, those who had to change medication due to adverse events during the study were also excluded. All patients provided informed consent, and the Ethics Committee of Affiliated Hospital of Nantong University approved the protocol.

\section{Study design}

Previous studies evaluating the correlation between BNP level and heart failure severity used $3000 \mathrm{pg} / \mathrm{mL}$ as the cut-off for extremely high BNP elevation $[8,9]$. In this open-label prospective cohort study we also used value of $3000 \mathrm{pg} / \mathrm{mL}$ (30 times the upper normal range) as the cut-off for stratifying patients into high and extra BNP groups. Enrolled patients were stratified into a high BNP group (BNP $\leq 3000 \mathrm{pg} / \mathrm{mL}$ ) or extra-high $\mathrm{BNP}$ group $(\mathrm{BNP}>3000 \mathrm{pg} / \mathrm{mL})$ depending on their admission plasma BNP levels. Each group was then subdivided into two subgroups (rhBNP or dobutamine) according to the intravenous administration of either rhBNP or dobutamine. Patients in the high and extra-high BNP groups were randomly assigned to rhBNP or dobutamine subgroups using a computer-generated random number table. In total, 58 patients were enrolled in the high BNP group, of which 28 were randomized to the rhBNP subgroup and 30 were randomized to the dobutamine subgroup. In addition, 47 patients were enrolled in the extra-high BNP group, of which 24 were randomized to the rhBNP subgroup and 23 were randomized to the dobutamine subgroup.

\section{Procedure}

In addition to conventional heart failure therapy, patients in the rhBNP and dobutamine subgroups received rhBNP (marketed as Xinhuosu, Chengdu Rhodiola BioPharmacy, Chengdu, China) and dobutamine (Shanghai No. 1 Biochemical \& Pharmaceutical, Shanghai, China) infusion, respectively, for a period of 24-72 h. rhBNP was administered as an intravenous bolus of $1.5 \mu \mathrm{g} / \mathrm{kg}$ followed by continuous infusion in doses of $0.0075-$ $0.01 \mu \mathrm{g} / \mathrm{kg} / \mathrm{min}$ according to each patient's clinical status. Patients in the dobutamine subgroup initially received $2.5 \mu \mathrm{g} / \mathrm{kg} / \mathrm{min}$ dobutamine and were uptitrated to $10 \mu \mathrm{g} / \mathrm{kg} / \mathrm{min}$ if hemodynamic goals were not achieved.

Plasma creatinine and BNP levels were measured at baseline and 5 days after the start of the study. Creatinine was detected by a creatinine assay kit (Abcam, MA, USA). BNP levels were determined with the ARCHITECT BNP Reagent Kit (Abbott Laboratories, IL, USA). Left ventricle end diastolic dimension (LVEDD) and left ventricular ejection fraction (LVEF) were measured by one observer blinded to the clinical data with a GE Vivid E9 ultrasound scanner (GE Healthcare, Horten, Norway) at the time of blood sample drawing.

\section{Assessment of efficacy}

The drug therapeutic efficacy was assessed as improvement of functional class; changes in BNP levels, LVEDD, and LVEF from baseline to fifth day after the beginning of treatment. According to the assessed dyspnea and systemic symptoms, the functional improvement was graded as "excellent" (NYHA class was improved $\geq 2$ functional classes), "improved" (NYHA class was improved 1 functional class) or "failed" (NYHA class remained the same or 
deteriorated). The overall effective rate was calculated as (patients with "excellent" + patients with "improved"/all patients) $\times 100 \%$.

In addition, the length of hospitalization and the effects of the study drugs on blood pressure, heart rate (HR), blood creatinine, and cardiovascular adverse events during infusion were also analyzed.

\section{Statistical analysis}

Statistical analysis was performed with SigmaStat 3.5 (Systat Software, Point Richmond, CA, USA) statistical software. Quantitative data are presented as mean \pm standard deviation (SD), while categorical data are presented as numbers. Comparisons between the two groups were made using a two-sample $t$-test for continuous variables and chi-squared test or Fishe exact test for categorical data. Differences between baseline and treatment values were assessed using a paired $t$-test. $P<0.05$ was considered significant.

\section{Results}

Baseline characteristics

In the extra-high BNP group, one patient who was assigned to the rhBNP subgroup had to withdraw from the study because of symptomatic hypotension $3 \mathrm{~h}$ after rhBNP administration; thus, 23 patients in the rhBNP subgroup finished this study. Basal blood pressure and plasma creatinine and baseline demographics and medical history information for patients in the high and extra-high BNP groups are summarized. Basal SBP level tended to be lower in the extra-high BNP group than in the high BNP group $(P=0.079)$, while plasma creatinine was significantly higher in the extra-high BNP group $(\mathrm{P}<0.01)$ (Table 1). However, the baseline characteristics of the patients and heart failure medications in patients randomized to the rhBNP subgroup or the dobutamine subgroup were well balanced in both the high and extra-high BNP groups (Table 2).

\section{Changes in NYHA class}

Functional improvements, as assessed by NYHA class, were observed so as to evaluate the therapeutic efficacy

Table 1 Baseline blood pressure and plasma creatinine in the high and Extra-high BNP groups

\begin{tabular}{lccc}
\hline Parameters & $\begin{array}{c}\text { High-BNP group } \\
(\mathbf{n}=\mathbf{5 8})\end{array}$ & $\begin{array}{c}\text { Extra-high BNP group } \\
(\mathbf{n}=\mathbf{4 6})\end{array}$ & P value* \\
\hline SBP $(\mathrm{mmHg})$ & $121.0 \pm 12.3$ & $116.7 \pm 12.5$ & 0.079 \\
DBP $(\mathrm{mmHg})$ & $72.9 \pm 7.2$ & $71.3 \pm 6.5$ & 0.229 \\
$\mathrm{Cr}(\mu \mathrm{mol} / \mathrm{L})$ & $81.6 \pm 30.7$ & $97.0 \pm 27.1$ & 0.009 \\
\hline
\end{tabular}

*Unpaired $t$ test.

Abbreviations: $B N P$ brain natriuretic peptide, $C r$ creatinine, $D B P$ diastolic blood pressure, SBP systolic blood pressure. of the treatments. Both rhBNP and dobutamine could effectively improve patient cardiac function. In the high BNP group, rhBNP was significantly more efficacious than dobutamine in improving NYHA class. The proportion of patients showing a functional improvement of at least 1 grade in NYHA class was significantly greater in the rhBNP subgroup $(92.86 \%, 26 / 28)$ than in the dobutamine subgroup $(70 \%, 21 / 30)(P<0.05)$. However, in the extra-high BNP group, the overall effective rates of the two subgroups did not differ significantly [56.52\% $(13 / 23)$ vs. $65.22(15 / 23)(P>0.05)]$ (Table 3$)$.

\section{Changes in blood BNP, LVEDD and LVEF in the high BNP group}

Changes in blood BNP, LVEDD, and LVEF were analyzed to assess the therapeutic efficacy. In the high BNP group, both rhBNP and dobutamine were able to significantly reduce the plasma BNP levels $(P<0.01)$, decrease LVEDD $(P<0.01)$, and increase $\operatorname{LVEF}(P<0.01)$. Compared to dobutamine, rhBNP was significantly more efficacious in reducing plasma BNP $(P<0.05)$ and increasing LVEF $(P<0.05)$, but the decrease of LVEDD in the rhBNP subgroup was similar to that of the dobutamine subgroup $(P>0.05)$ (Table 4).

\section{Changes in blood BNP, LVEDD and LVEF in the extra-high BNP group}

The measurement range for the ARCHITECT BNP assay is $10-5000 \mathrm{pg} / \mathrm{mL}$. In the extra-high BNP group, there were 10 patients (6 from the dobutamine subgroup and 4 from the rhBNP subgroup) whose plasma BNP levels were $>5000 \mathrm{pg} / \mathrm{mL}$ before the study; therefore, as we only selected patients with plasma BNP levels $\leq 5000 \mathrm{pg} / \mathrm{mL}$ for statistical analyses of BNP changes, their BNP levels could not be used for calculating the mean BNP values. Nonetheless, the changes in LVEDD and LVEF were still analyzed in all enrolled patients. Of the 10 patients with plasma BNP $>5000 \mathrm{pg} / \mathrm{mL}$, there were 5 and 3 patients in the dobutamine and rhBNP subgroups, respectively, whose plasma BNP levels were reduced to $<5000 \mathrm{pg} / \mathrm{mL}$. The average plasma BNP level in the rhBNP subgroup was slightly, but not significantly, higher than that of the dobutamine subgroup $(4020 \pm 710 \mathrm{pg} / \mathrm{mL}$ vs. $3508 \pm 654 \mathrm{pg} / \mathrm{mL}$; $P>0.05)$ at day 5 after treatment. Similarly, the BNP levels in patients with plasma $\mathrm{BNP} \leq 5000 \mathrm{pg} / \mathrm{mL}$ was effectively reduced by rhBNP and dobutamine $(P<0.01)$ (Table 5). In addition, both rhBNP and dobutamine slightly, but significantly decreased the LVEDD $(P<0.05)$, and significantly increased the LVEF $(P<0.05)$ of all enrolled patients. The therapeutic efficacy of dobutamine in improving these parameters tended to be better than that of rhBNP, although the difference was not statistically significant $(P>0.05)$ (Table 5). 
Table 2 Baseline characteristics and treatment information

\begin{tabular}{|c|c|c|c|c|c|c|}
\hline \multirow[t]{2}{*}{ Characteristics } & \multicolumn{3}{|c|}{ High BNP group } & \multicolumn{3}{|c|}{ Extra-high BNP group } \\
\hline & $\begin{array}{c}\text { Dobutamine } \\
(n=30)\end{array}$ & $\begin{array}{l}\text { rhBNP } \\
(n=28)\end{array}$ & $P$ value & $\begin{array}{l}\text { Dobutamine } \\
(n=23)\end{array}$ & $\begin{array}{l}\text { rhBNP } \\
(n=23)\end{array}$ & $P$ value \\
\hline Age (y) & $63 \pm 13$ & $65 \pm 13$ & $0.495+$ & $68 \pm 14$ & $67 \pm 12$ & $0.709+$ \\
\hline Male/female & $19 / 11$ & $18 / 10$ & $0.843 \neq$ & $15 / 8$ & $16 / 7$ & $0.935 \neq$ \\
\hline \multicolumn{7}{|l|}{ HF etiology } \\
\hline IDC & 13 & 11 & $0.963 \neq$ & 10 & 12 & $0.768 \neq$ \\
\hline $\mathrm{CHD}$ & 8 & 10 & $0.645 \ddagger$ & 10 & 8 & $0.763 \neq$ \\
\hline FVM & 2 & 1 & $1.000 \S$ & 0 & 1 & $1.000 \S$ \\
\hline $\mathrm{HHD}$ & 1 & 2 & $0.605 \S$ & 0 & 1 & $1.000 \S$ \\
\hline Valvulopathy & 6 & 4 & $0.732 \S$ & 3 & 1 & $0.608 \S$ \\
\hline NHYA & & & $0.645 \ddagger$ & & & $0.489 \S$ \\
\hline III & 8 & 10 & & 0 & 2 & \\
\hline IV & 22 & 18 & & 23 & 21 & \\
\hline \multicolumn{7}{|c|}{ Concomitant medications } \\
\hline ACEI & 14 & 16 & $0.593 \neq$ & 14 & 12 & $0.766 \neq$ \\
\hline ARB & 12 & 7 & $0.349 \neq$ & 5 & 8 & $0.513 \neq$ \\
\hline Digitalis & 24 & 23 & $0.899 \neq$ & 18 & 20 & $0.699 \S$ \\
\hline$\beta$-blockers & 11 & 14 & $0.448 \neq$ & 4 & 6 & $0.722 \S$ \\
\hline \multicolumn{7}{|l|}{ Spironolactone } \\
\hline $20(\mathrm{mg} / \mathrm{d})$ & 15 & 18 & $0.405 \ddagger$ & 11 & 6 & $0.324 \ddagger$ \\
\hline $40(\mathrm{mg} / \mathrm{d})$ & 10 & 8 & $0.914 \ddagger$ & 10 & 12 & $0.768 \neq$ \\
\hline Average dosage & $28.0 \pm 10.0$ & $26.2 \pm 9.4$ & $0.500+$ & $29.5 \pm 10.2$ & $33.3 \pm 9.7$ & $0.243+$ \\
\hline \multicolumn{7}{|l|}{ Furosemide (mg/d) } \\
\hline $20(\mathrm{mg} / \mathrm{d})$ & 12 & 15 & $0.440 \neq$ & 7 & 4 & $0.328 \S$ \\
\hline $40(\mathrm{mg} / \mathrm{d})$ & 11 & 8 & $0.707 \neq$ & 11 & 9 & $0.766 \neq$ \\
\hline $80(\mathrm{mg} / \mathrm{d})$ & 2 & 3 & $0.665 \S$ & 3 & 5 & $0.699 \S$ \\
\hline Average dosage & $33.6 \pm 17.0$ & $33.1 \pm 19.5$ & $0.919+$ & $39.0 \pm 19.5$ & $46.7 \pm 22.8$ & $0.267 \dagger$ \\
\hline
\end{tabular}

†Unpaired $t$-test; $\neq C h$-square test; §Fisher exact test.

Abbreviations: $A C E I$ angiotensin-converting enzyme inhibitor, $A R B$ angiotensin II receptor blocker, $B N P$ brain natriuretic peptide, $C H D$ coronary heart disease, $H F$ heart failure, HHD hyperthyroid heart disease, IDC idiopathic dilated cardiomyopathy, NHYA New York Heart Association, rhBNP recombinant human brain natriuretic peptide. Values are expressed as number or mean \pm SD.

\section{Length of hospitalization and All cause mortality}

No patients died during administration of dobutamine or rhBNP. One patient with dilated cardiomyopathy in the extra-high BNP group whose symptoms were much improved by dobutamine suffered sudden death due to ventricular fibrillation at 8 days after withdrawal of dobutamine infusion during hospitalization; we excluded this patient from analysis of hospitalization length. In the high BNP group, length of hospitalization for rhBNPtreated patients was significantly shorter than for patients treated with dobutamine $(8.0 \pm 1.9$ versus $9.3 \pm 2.2$ days, $\mathrm{P}<0.05)$. However, in the extra-high $\mathrm{BNP}$ group, the length of hospitalization was not significantly different between the two subgroups $(13.0 \pm 3.1$ versus $12.2 \pm$ 2.7 days, $\mathrm{P}>0.05)$. All-cause mortality during hospitalization was similar between the dobutamine and rhBNP

Table 3 Changes in NYHA class from baseline to day 5 after treatment

\begin{tabular}{|c|c|c|c|c|c|c|c|c|c|c|}
\hline \multirow[t]{2}{*}{ Groups } & \multicolumn{5}{|c|}{ Dobutamine } & \multicolumn{5}{|c|}{ rhBNP } \\
\hline & Total & Ex & Im & $\mathrm{Fa}$ & OER (\%) & Total & Ex & Im & $\mathrm{Fa}$ & OER (\%) \\
\hline High BNP & 30 & 12 & 9 & 9 & $21(70.00)$ & 28 & 9 & $17^{*}$ & 2 & $26(92.86)^{*}$ \\
\hline Extra-high BNP & 23 & 6 & 9 & 8 & $15(65.22)$ & 23 & 5 & 8 & 10 & $13(56.52)$ \\
\hline
\end{tabular}


Table 4 Changes in blood BNP, LVEDD, and LVEF in the high BNP group

\begin{tabular}{lccccccc}
\hline Parameters & \multicolumn{3}{c}{ Dobutamine $(\mathbf{n}=\mathbf{3 0})$} & & \multicolumn{3}{c}{ rhBNP $(\mathbf{n}=\mathbf{2 8})$} \\
\cline { 2 - 4 } & Baseline & 5 Days & Changes & & Baseline & 5 Days & Changes \\
\hline BNP $(\mathrm{pg} / \mathrm{mL})$ & $1890 \pm 742$ & $1261 \pm 560^{* *}$ & $629 \pm 715$ & & $1819 \pm 665$ & $843 \pm 450^{* * \Delta \Delta}$ & $976 \pm 566^{\Delta}$ \\
LVEDD $(\mathrm{mm})$ & $63.8 \pm 4.6$ & $61.2 \pm 6.5^{* *}$ & $2.6 \pm 4.3$ & & $64.3 \pm 4.9$ & $60.9 \pm 5.7^{* *}$ & $3.3 \pm 3.2$ \\
LVEF (\%) & $32.1 \pm 6.1$ & $39.6 \pm 10.9^{* *}$ & $7.5 \pm 8.1$ & & $31.3 \pm 6.8$ & $43.7 \pm 11.2^{* *}$ & $12.4 \pm 7.5^{\Delta}$ \\
\hline
\end{tabular}

Abbreviations: $L V E D D$ left ventricle end diastolic dimension, $L V E F$ left ventricular ejection fraction, Other abbreviations are same as in Table 2 . Values are mean \pm SD.

${ }^{* *} \mathrm{P}<0.01$ (paired $t$ - test) versus baseline; ${ }^{\Delta} \mathrm{P}<0.05,{ }^{\Delta \Delta} \mathrm{P}<0.01$ (unpaired $t$ - test) versus dobutamine.

subgroups in the high and extra-high BNP groups (both $\mathrm{P}=1.000)$.

\section{Effects of the study drugs on blood pressure, HR and plasma creatinine}

Ambulatory changes in systolic blood pressure (SBP), diastolic blood pressure (DBP), and HR were monitored during infusion. The SBP, DBP, and HR values at the end of infusion and the levels of plasma creatinine at day 5 after treatment were measured. Both rhBNP and dobutamine did not significantly affect $H R$ and plasma creatinine $(P>0.05)$. The systolic and diastolic pressure were significantly decreased by rhBNP $(P<0.01)$, while no significant changes were observed in dobutamine-treated patients $(P>0.05)$ (Table 6).

\section{Cardiovascular adverse events}

The incidence of selected cardiovascular adverse events during administration was similar between the rhBNPand dobutamine-treated patients. However, symptomatic hypotension tended to be more common in the rhBNPtreated patients than the dobutamine-treated patients, although the difference was not statistically significant (Table 7). In the extra-high BNP group, one patient who was initially enrolled to the rhBNP subgroup had to withdraw from this study due to symptomatic hypotension. We still included this patient in the statistical analysis of adverse events.

\section{Discussion}

Our study is the first to compare the effects of rhBNP and dobutamine on ADHF patients with different plasma BNP levels. The results revealed that rhBNP was not superior to the traditional inotropic agent dobutamine at improving cardiac function in patients with extra-high BNP levels (>3000 pg/mL). On the contrary, rhBNP-treated patients tended to be more likely to experience hypotension than dobutamine-treated patients.

Dobutamine, a dopamine derivative, produces positive inotropic and chronotropic effects on myocardium mainly through stimulation of $\beta 1$-receptors and by causing a reflex decrease in sympathetic tone $[1,10,11]$. At low doses, dobutamine induces mild arterial vasodilatation, which augments stroke volume by reductions in afterload [4], and has little influence on HR, blood pressure, and cardiovascular adverse events.

BNP, a natriuretic peptide, is produced and released from the ventricles in response to increased wall stretch and tension [2]. It binds to the A-type natriuretic peptide receptor that is present on the surface of vascular smooth muscle and endothelial cells [2], resulting in activation of guanylate cyclase and the subsequent accumulation of intracellular cyclic GMP in target tissues [12]. Cyclic GMP, as a second messenger, mediates natriuretic, diuretic and smooth muscle relaxant effects, which lead to the therapeutic benefits of venous and arterial vasodilation and decreases in preload and afterload, resulting in increased cardiac output with improved dyspnea and systemic symptoms [12].

In addition, BNP also serves as a physiological antagonist of the renin-angiotensin-aldosterone system and the sympathetic nervous system [13]. It inhibits reninaldosterone secretion, suppresses the sympathetic nervous system, and antagonizes the action of antidiuretic hormone in inducing antidiuresis, antinatriuresis, and vasoconstriction, leading to a decrease in systemic vascular resistance and cardiac pre- and afterload $[4,14,15]$. Thus, as a compensatory mechanism for heart failure, circulating BNP levels strongly correlate with the severity of heart failure $[16,17]$.

Table 5 Changes in blood BNP, LVEDD, and LVEF in the extra-high BNP group

\begin{tabular}{|c|c|c|c|c|c|c|}
\hline \multirow[t]{2}{*}{ Parameters } & \multicolumn{3}{|c|}{ Dobutamine $(n=23)$} & \multicolumn{3}{|c|}{$\operatorname{rhBNP}(n=23)$} \\
\hline & Baseline & 5 Days & Changes & Baseline & 5 Days & Changes \\
\hline$\overline{B N P}(\mathrm{pg} / \mathrm{mL})$ & $3790 \pm 740$ & $2806 \pm 859^{* *}$ & $985 \pm 931^{\S}$ & $3912 \pm 726$ & $3207 \pm 900^{* *}$ & $705 \pm 884^{*}$ \\
\hline LVEDD $(\mathrm{mm})$ & $66.6 \pm 5.1$ & $64.2 \pm 5.1^{*}$ & $2.4 \pm 4.6$ & $67.7 \pm 5.4$ & $65.6 \pm 6.3^{*}$ & $2.1 \pm 4.2$ \\
\hline LVEF (\%) & $24.4 \pm 5.7$ & $31.6 \pm 6.9^{* *}$ & $7.2 \pm 6.1$ & $23.8 \pm 5.6$ & $29.0 \pm 6.5^{* *}$ & $5.2 \pm 7.1$ \\
\hline
\end{tabular}

Abbreviations are same as in Table 2 and Table 4. Values are mean $\pm S D .{ }^{5} n=17,{ }^{*} n=19 .{ }^{*} P<0.05,{ }^{* *} P<0.01$ (paired $t$ - test) versus baseline. 
Table 6 Effects of the study drugs on blood pressure $(\mathrm{mmHg}), \mathrm{HR}(\mathrm{bpm})$ and plasma creatinine $(\mu \mathrm{mol} / \mathrm{L})$

\begin{tabular}{|c|c|c|c|c|c|c|c|c|}
\hline \multirow[t]{3}{*}{ Parameters } & \multicolumn{4}{|c|}{ High BNP group } & \multicolumn{4}{|c|}{ Extra-high BNP group } \\
\hline & \multicolumn{2}{|c|}{ Dobutamine $(n=30)$} & \multicolumn{2}{|c|}{$\operatorname{rhBNP}(n=28)$} & \multicolumn{2}{|c|}{ Dobutamine $(n=23)$} & \multicolumn{2}{|c|}{$\operatorname{rhBNP}(n=23)$} \\
\hline & Baseline & 5 Days & Baseline & 5 Days & Baseline & 5 Days & Baseline & 5 Days \\
\hline SBP & $119.3 \pm 12.7$ & $121.3 \pm 12.0$ & $122.9 \pm 11.9$ & $115.4 \pm 12.4^{* *}$ & $114.8 \pm 11.9$ & $116.0 \pm 12.5$ & $118.6 \pm 13.0$ & $113.2 \pm 13.2^{* *}$ \\
\hline DBP & $72.4 \pm 6.8$ & $74.3 \pm 5.3$ & $73.5 \pm 7.7$ & $69.6 \pm 7.9^{* *}$ & $70.7 \pm 6.7$ & $71.8 \pm 6.6$ & $71.9 \pm 6.5$ & $68.7 \pm 6.6^{* *}$ \\
\hline $\mathrm{HR}$ & $77.6 \pm 12.5$ & $80.3 \pm 13.1$ & $81.8 \pm 11.1$ & $83.9 \pm 11.5$ & $83.2 \pm 13.9$ & $85.7 \pm 13.0$ & $82.3 \pm 12.4$ & $84.6 \pm 9.3$ \\
\hline $\mathrm{Cr}$ & $84.4 \pm 29.8$ & $79.3 \pm 20.4$ & $78.5 \pm 31.9$ & $80.9 \pm 26.3$ & $95.4 \pm 24.4$ & $90.3 \pm 23.3$ & $98.6 \pm 30.1$ & $105.5 \pm 32.9$ \\
\hline
\end{tabular}

Abbreviations: $H R$ heart rate. Other abbreviations are same as in Table 1 and Table 2 . Values are mean \pm SD. ${ }^{* *} \mathrm{P}<0.01$ (paired $t$ - test) versus baseline.

rhBNP has the same 32 amino acid sequence and biological activity as endogenous BNP, with a mean terminal elimination half-life of $18-20$ min $[18,19]$, which means that it is almost completely cleared at $3 \mathrm{~h}$ post infusion withdrawal (approximately 9-10 elimination half-lives). Several studies indicated that BNP changes during the first 5 days of hospitalization had a very high prognostic value in patients with heart failure $[20,21]$. Accordingly, we assayed the plasma BNP levels at day 5 after treatment to evaluate the efficacy of rhBNP and dobutamine. At this time, the exogenous rhBNP had been completely eliminated and did not interfere with the measurement of the endogenous BNP level, allowing accurate assessment of the therapeutic efficacy of the study drugs.

Numerous studies reported that BNP levels reflect heart failure severity $[16,17,22]$. However, Law et al. found that extremely high BNP level $(>3000 \mathrm{pg} / \mathrm{mL})$ did not correlate with heart failure severity when patients had complications such as neurological disorder, sepsis, or subarachnoid hemorrhage. The possible reasons might be that in these patients, an increase in sympathetic stimulation causes the hypothalamus to secrete excess vasopressin and BNP [9,23]. In our study, all patients with these confounders were excluded. Thus, BNP level might well reflect the status of heart function.
We found that rhBNP was more efficient than dobutamine at improving heart function in patients with BNP levels $\leq 3000 \mathrm{pg} / \mathrm{mL}$. However, their efficacies were similar in patients with extra-high BNP levels. The difference might be explained by the following reasons. First, BNP exerts its biological activities through binding to the Atype natriuretic peptide receptor, which is present on the surface of vascular smooth muscle and endothelial cells [2]. When the compensatorily increased endogenous BNP is not sufficient to bind to all the free receptors, the introduced exogenous BNP (rhBNP) can fully activate the remaining free receptors, resulting in a marked improvement in heart function. However, when the circulating BNP increases to even greater levels, with subsequent full activation of their receptors, an insufficient number of free BNP receptors can be bound by exogenous BNP, meaning that the additional effects of exogenous BNP on decreasing cardiac pre- and afterload are inhibited. Second, patients with extremely high BNP levels might be resistant to the biological action of BNP. This phenomenon is characterized by extremely high circulating BNP levels in patients with congestive heart failure who have physical signs of fluid retention and vasoconstriction from poor biological activity of the BNP system [14]. A deficient response to BNP is attributed to inactivation of BNP by plasma and tissue proteases

Table 7 Selected cardiovascular adverse events during drug administration

\begin{tabular}{|c|c|c|c|c|c|c|}
\hline \multirow[t]{2}{*}{ Adverse events } & \multicolumn{3}{|c|}{ High BNP group } & \multicolumn{3}{|c|}{ Extra-high BNP group } \\
\hline & Dobutamine $(n=30)$ & $\operatorname{rhBNP}(n=28)$ & $P$ value & Dobutamine $(n=23)$ & rhBNP $(n=24)$ & $P$ value \\
\hline Symptomatic hypotension & 0 & 0 & 1.000 & 0 & 1 & 1.000 \\
\hline Asymptomatic hypotension & 0 & 2 & 0.229 & 0 & 3 & 0.234 \\
\hline Sustained VT & 0 & 0 & 1.000 & 0 & 0 & 1.000 \\
\hline Nonsustained VT & 2 & 0 & 0.492 & 2 & 1 & 0.609 \\
\hline VF & 0 & 0 & 1.000 & 0 & 0 & 1.000 \\
\hline Sudden death & 0 & 0 & 1.000 & 0 & 0 & 1.000 \\
\hline Cardiac arrest & 0 & 0 & 1.000 & 0 & 0 & 1.000 \\
\hline
\end{tabular}

Abbrevations: VF ventricular fibrillation, $V T$ ventricular tachycardia, Other abbreviations are same as in Table 2 . Fisher exact text was used. 
before they bind to their receptors, downregulation or desensitization of BNP-specific receptors, and mechanisms that counteract the biological effects of BNP at postreceptor level [14]. Third, patients with extremely high BNP levels usually suffer from more severe heart failure, accompanied by serious renal congestion and low renal blood flow [24], which could inhibit the effects of rhBNP on renal vessel dilation, natriuresis, and diuresis, but would not affect the positive inotropic effects of dobutamine on myocardium. In this study, basal plasma creatinine was significantly higher in the extra-high BNP group, suggesting deterioration of renal function might be responsible for the low efficiency of rhBNP in patients with extremely high BNP. In addition, patients with more severe heart failure usually also have lower arterial pressure. The SBP level in the extra-high BNP group tended to be lower than in the high BNP group, although the difference was not significant $(P=0.079)$. Vasodilator drugs such as rhBNP might lead to more satisfactory clinical improvements in heart failure patients with high-normal blood pressure.

The blood pressure in the rhBNP subgroup was decreased after treatment (Table 6). One patient in the extra-high BNP group with low baseline blood pressure $(96 / 64 \mathrm{mmHg})$ experienced symptomatic hypotension $(84 / 50 \mathrm{mmHg})$ at $3 \mathrm{~h}$ after rhBNP infusion and had to withdraw from the study. Plasma creatinine remained unchanged in patients with plasma BNP $\leq 3000 \mathrm{pg} / \mathrm{mL}$ after treatment, but it tended to increase in patients with extra-high BNP levels after rhBNP treatment (Table 6). One male patient in the extra-high BNP group who received rhBNP had an increase in plasma creatinine from $165 \mu \mathrm{mol} / \mathrm{L}(1.9 \mathrm{mg} / \mathrm{dl}$, baseline) to $243 \mu \mathrm{mol} / \mathrm{L}$ $(2.7 \mathrm{mg} / \mathrm{dl})$. These results indicate that rhBNP, as an antagonist of the renin-angiotensin-aldosterone system (RAAS), might impair renal function and induce azotemia in patients with severe heart failure whose renal function depends on RAAS. Dobutamine had no obvious effect on plasma creatinine.

\section{Study limitations}

The results of this study are limited by its open-label design and the relatively small number of patients in each subgroup. Moreover, the effects of rhBNP and dobutamine on hospital readmissions and long-term survival were not assessed. More information from a larger blinded study will be required to confirm the results of this study.

\section{Conclusions}

We found that rhBNP was more efficient than dobutamine in ADHF patients who had plasma BNP $\leq 3000 \mathrm{pg} / \mathrm{mL}$. However, rhBNP therapy was not superior to dobutamine when BNP reached extremely high level $(>3000 \mathrm{pg} / \mathrm{mL})$.

\section{Abbreviations}

ADHF: Acute decompensated heart failure; CHD: Coronary heart disease; DBP: Diastolic blood pressure; FVM: Fulminant viral myocarditis; HHD: Hyperthyroid heart disease; HR: Heart rate; IDC: Idiopathic dilated cardiomyopathy; LVEDD: Left ventricular end diastolic diameter; LVEF: Left ventricular ejection fraction; NYHA: New York Heart Association; RAAS: Reninangiotensin-aldosterone system; rhBNP: Recombinant human B-type natriuretic peptide; SBP: Systolic blood pressure.

\section{Competing interests}

The authors declare that they have no competing interests.

\section{Authors' contributions}

PHY conceived and designed the study, analyzed and interpreted the data, drafted the manuscript and critically revised the manuscript for intellectual content. ZJH was responsible for acquisition, analysis and interpretation of data, drafting of the manuscript, and final approval of the published version. GY was responsible for analysis and interpretation of data and critical revision of the manuscript. YXH and PM inspected and approved the final version of the manuscript. NHY was responsible for analysis and interpretation of data. All authors read and approved the final manuscript.

\section{Acknowledgement}

This work was supported by the Special Coordination Funds for 226 Project of Nantong City.

\section{Author details}

${ }^{1}$ Department of Cardiology, Affiliated Hospital of Nantong University, and Institute of Cardiovascular Research, Nantong University, Jiangsu 226001, China. 2Department of Echocardiography, Affiliated Hospital of Nantong University, Jiangsu, China.

Received: 15 December 2013 Accepted: 26 February 2014 Published: 4 March 2014

\section{References}

1. Leier CV, Unverferth DV: Drugs five years later: dobutamine. Ann Intern Med 1983, 99:490-496.

2. Arora S, Clarke K, Srinivasan V, Gradman A: Effect of nesiritide on renal function in patients admitted for decompensated heart failure. QJM 2007, 100:699-706.

3. Colucci WS: Nesiritide for the treatment of decompensated heart failure. J Card Fail 2001, 7:92-100.

4. Nieminen MS, Böhm M, Cowie MR, Drexler H, Filippatos GS, Jondeau G, Hasin Y, Lopez-Sendon J, Mebazaa A, Metra M, Rhodes A, Swedberg K, Priori SG, Garcia MA, Blanc JJ, Budaj A, Cowie MR, Dean V, Deckers J, Burgos EF, Lekakis J, Lindahl B, Mazzotta G, Morais J, Oto A, Smiseth OA, Garcia MA, Dickstein K, Albuquerque $A$, Conthe $P$, et al: Executive summary of the guidelines on the diagnosis and treatment of acute heart failure: the Task Force on Acute Heart Failure of the European Society of Cardiology. Eur Heart $J$ 2005, 26:384-416.

5. Silver MA, Horton DP, Ghali JK, Elkayam U: Effect of nesiritide versus dobutamine on short-term outcomes in the treatment of patients with acutely decompensated heart failure. J Am Coll Cardiol 2002, 39:798-803.

6. Burger AJ, Elkayam U, Neibaur MT, Haught H, Ghali J, Horton DP, Aronson $D$ : Comparison of the occurrence of ventricular arrhythmias in patients with acutely decompensated congestive heart failure receiving dobutamine versus nesiritide therapy. Am J Cardiol 2001, 88:35-39.

7. Burger AJ, Horton DP, LeJemtel T, Ghali JK, Torre G, Dennish G, Koren M, Dinerman J, Silver M, Cheng ML, Elkayam U: Effect of nesiritide (B-type natriuretic peptide) and dobutamine on ventricular arrhythmias in the treatment of patients with acutely decompensated congestive heart failure: the PRECEDENT study. Am Heart J 2002, 144:1102-1108.

8. Guglin M, Hourani R, Pitta S: Factors determining extreme brain natriuretic peptide elevation. Congest Heart Fail 2007, 13:136-141.

9. Law C, Glover C, Benson K, Guglin M: Extremely high brain natriuretic peptide does not reflect the severity of heart failure. Congest Heart Fail 2010, 16:221-225

10. Nakajima-Takenaka C, Sakata S, Kato S, Ohga Y, Murata KY, Taniguchi S: Detrimental effects after dobutamine infusion on rat left ventricular function: mechanical work and energetics. Exp Physiol 2005, 90:635-644. 
11. Ruffolo RR Jr: The pharmacology of dobutamine. Am J Med Sci 1987, 294:244-248.

12. Michaels AD, Klein A, Madden JA, Chatterjee K: Effects of intravenous nesiritide on human coronary vasomotor regulation and myocardial oxygen uptake. Circulation 2003, 107:2697-2701.

13. Omland T, Hagve TA: Natriuretic peptides: physiologic and analytic considerations. Heart Fail Clin 2009, 5:471-487.

14. Clerico A, Recchia FA, Passino C, Emdin M: Cardiac endocrine function is an essential component of the homeostatic regulation network: physiological and clinical implications. Am J Physiol Heart Circ Physiol 2006, 290:H17-H29.

15. Fermepín MR, Vatta MS, Bianciotti LG, Wolovich TJ, Fernández BE: B-Type and C-type natriuretic peptides modify norepinephrine uptake in discrete encephalic nuclei of the rat. Cell Mol Neurobiol 2000, 20:763-771.

16. Maisel A: B-type natriuretic peptide levels: diagnostic and prognostic in congestive heart failure: what's next? Circulation 2002, 105:2328-2331.

17. Cowie MR, Jourdain P, Maisel A, Dahlstrom U, Follath F, Isnard R, Luchner A, McDonagh T, Mair J, Nieminen M, Francis G: Clinical applications of B-type natriuretic peptide (BNP) testing. Eur Heart J 2003, 24:1710-1718.

18. Reichert S, Ignaszewski A: Molecular and physiological effects of nesiritide. Can J Cardiol 2008, 24(Suppl B):15B-18B.

19. DeWald TA, Hernandez AF: Efficacy and safety of nesiritide in patients with acute decompensated heart failure. Expert Rev Cardiovasc Ther 2010, 8:159-169.

20. Cohen-Solal A, Logeart D, Huang B, Cai D, Nieminen MS, Mebazaa A: Lowered B-type natriuretic peptide in response to levosimendan or dobutamine treatment is associated with improved survival in patients with severe acutely decompensated heart failure. J Am Coll Cardiol 2009, 53:2343-2348.

21. Valle R, Aspromonte N, Giovinazzo P, Carbonieri E, Chiatto M, di Tano G, Feola M, Milli M, Fontebasso A, Barro S, Bardellotto S, Milani L: B-type natriuretic Peptide-guided treatment for predicting outcome in patients hospitalized in sub-intensive care unit with acute heart failure. J Card Fail 2008, 14:219-224.

22. Cheng V, Kazanagra R, Garcia A, Lenert L, Krishnaswamy P, Gardetto N, Clopton P, Maisel A: A rapid bedside test for B-type peptide predicts treatment outcomes in patients admitted for decompensated heart failure: a pilot study. J Am Coll Cardiol 2001, 37:386-391.

23. Benvenga $\mathrm{S}$ : What is the pathogenesis of hyponatremia after subarachnoid hemorrhage? Nat Clin Pract Endocrinol Metab 2006, 2:608-609.

24. Clerico A: Pathophysiological and clinical relevance of circulating levels of cardiac natriuretic hormones: is their assay merely a marker of cardiac disease? Clin Chem Lab Med 2002, 40:752-760.

doi:10.1186/1471-2261-14-31

Cite this article as: Pan et al: Comparative effects of recombinant human brain natriuretic peptide and dobutamine on acute decompensated heart failure patients with differsent blood BNP levels. BMC Cardiovascular Disorders 2014 14:31.

\section{Submit your next manuscript to BioMed Central and take full advantage of:}

- Convenient online submission

- Thorough peer review

- No space constraints or color figure charges

- Immediate publication on acceptance

- Inclusion in PubMed, CAS, Scopus and Google Scholar

- Research which is freely available for redistribution 